\title{
Publisher Correction: Finding influential nodes for integration in brain networks using optimal percolation theory
}

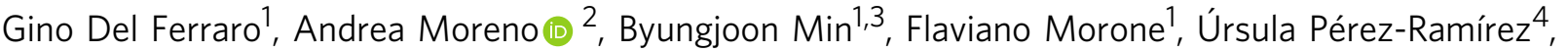 \\ Laura Pérez-Cervera², Lucas C. Parra (10 ${ }^{5}$, Andrei Holodny (iD ${ }^{6}$, Santiago Canals ${ }^{2} \&$ Hernán A. Makse ${ }^{1}$
}

Correction to: Nature Communications https://doi.org/10.1038/s41467-018-04718-3; published online: 11 June 2018

The original version of this Article contained an error in the last sentence of the first paragraph of the Introduction, which incorrectly read 'Correlation of brain activity is typically measured using functional magnetic resonance imaging (fMRI), and the correlation structure is often referred to as "fu'. The correct version states 'referred to as "functional connectivity" ${ }^{-6}$ ' in place of 'referred to as "fu'. This has been corrected in both the PDF and HTML versions of the Article.

Published online: 03 August 2018

\begin{abstract}
(c) Open Access This article is licensed under a Creative Commons Attribution 4.0 International License, which permits use, sharing, adaptation, distribution and reproduction in any medium or format, as long as you give appropriate credit to the original author(s) and the source, provide a link to the Creative Commons license, and indicate if changes were made. The images or other third party material in this article are included in the article's Creative Commons license, unless indicated otherwise in a credit line to the material. If material is not included in the article's Creative Commons license and your intended use is not permitted by statutory regulation or exceeds the permitted use, you will need to obtain permission directly from the copyright holder. To view a copy of this license, visit http://creativecommons.org/licenses/by/4.0/.
\end{abstract}

(C) The Author(s) 2018

\footnotetext{
${ }^{1}$ Levich Institute and Physics Department, City College of New York, New York, NY 10031, USA. ${ }^{2}$ Instituto de Neurociencias, CSIC and UMH, 03550 San Juan de Alicante, Spain. ${ }^{3}$ Department of Physics, Chungbuk National University, Cheongju, Chungbuk 28644, Korea. ${ }^{4}$ Center for Biomaterials and Tissue Engineering, UPV, Valencia 46022, Spain. ${ }^{5}$ Biomedical Engineering, City College of New York, New York, NY 10031, USA. ${ }^{6}$ Department of Radiology, Memorial Sloan Kettering Cancer Center, New York, NY 10065, USA. These authors contributed equally: Gino Del Ferraro, Andrea Moreno. Correspondence and requests for materials should be addressed to S.C. (email: scanals@umh.es) or to H.A.M. (email: hmakse@lev.ccny.cuny.edu)
} 